\title{
STUDYING THE MOTION WITH TIME-VARIABLE ACCELERATION
}

\section{ESTUDANDO O MOVIMENTO COM ACELERAÇÃO VARIADA NO TEMPO}

\author{
ANDERSON CORTEZ-CALDERINI ${ }^{\mathrm{a}}$ \\ CELIA MARTINS CORTEZ ${ }^{\mathrm{b}}$
}

\begin{abstract}
Resumo
Neste trabalho é feita uma exposição didática do desenvolvimento diferencial/integral, que leva ao modelo matemático que descreve o movimento retilíneo em sua forma mais geral, tomando como ponto de partida o conceito bem conhecido da aceleração como a taxa de variação da velocidade.
\end{abstract}

Palavras-chave: movimento retilíneo, movimento de aceleração variada, equação geral.

\begin{abstract}
In this work a didactic exposition of the differential/integral development is made, which leads to a mathematical model that describes the rectilinear motion in its most general form, taking as a starting point the well-known concept of acceleration as the rate of change of velocity.
\end{abstract}

Keywords: rectilinear motion, variable acceleration motion, general equation.

MSC2010: 70B10, 70-03, 70-01

\section{Introduction}

The study of the behavior of a phenomenon involving several variables starts, in general, by changing the value of one of them, while the values of the others are kept constant. Based on this method, Galileo introduced the concept of acceleration, showing that the velocity varied with time according to the equation: $a={ }^{\circ} \mathrm{V} /{ }^{\circ} \mathrm{t}$, thus conceptualizing the acceleration of a material body as the rate of change of its velocity with respect to time [1,2].

In search of a more favorable condition for investigating the behavior of objects in free fall, Galileo used the inclined plane to analyze naturally accelerated downward

\footnotetext{
${ }^{\text {a }}$ Federal Center for Technological Education, Rio de Janeiro, Brazil: E-mail: ansocortez@gmail.com

${ }^{\mathrm{b}}$ Institute of Mathematics and Statistics, Rio de Janeiro State University, Rio de Janeiro, Brazil; ORCID:0000-0002-

7857-1167, E-mail: ccortezs@ime.uerj.br
} 
motion. Thus, he found that the distance travelled by an object in uniformly accelerated motion increases directly with the square of the time spent moving, and that the speed of a free-falling object depends only on the height at which it begins its fall. [1,2]

Later, Newton showed the origin of acceleration, when he related it to the force acting on the body, which makes its speed vary. He also evidenced the inverse relationship of this variation with the body mass, as expressed by his second law: a $=\mathrm{F}$ / m. In this one, acceleration also presents itself as a rate of change, now between the acting force and the mass of the body. [2,3]

In his studies of Kinematics, Newton related the displacement, velocity and acceleration of bodies through the formalism of differential and integral calculus, being the first scholar dedicated to the development of this very valuable mathematical tool [4]. He also introduced the concepts of force, impulse, energy and potency [3].

It is known that acceleration can be positive or negative and that velocity has vector representation [5]. But, regardless of the signal, an interesting question is the relation of velocity and displacement of a body, or a material particle, with acceleration, when it varies in time, and therefore cannot be taken as a rate of velocity variation.

The objective of this work is to expose the differential/integral development that leads to the mathematical model capable of describing the time-varying rectilinear motion in its most general form.

\section{Uniformly Accelerated Motion - UAM}

Starting from the concept of acceleration (a) as the rate of change of velocity over time, we can write that

$$
d v=a d t
$$

whose integration [6] provides the well-known equation that describes the velocity in UAM:

$$
v(t)=v_{o}+a t,
$$


where $v_{o}$ corresponds to the initial velocity (for $\mathrm{t}=0$ ). Considering the differential equation of motion of a body, $d S=v(t) d t$, substituting Eq. 1 into this and integrating, $\int d S=\int\left(v_{o}+a t\right) d t$, we get

$$
S=v_{o} t+\frac{a t^{2}}{2}+S_{o}
$$

which is precisely the equation used to calculate the displacement $(S)$ of the body in the UAM, where $S_{o}$ is the integration constant that corresponds to the initial position of the body/particle (for $\mathrm{t}=0$ ).

\section{Variable Acceleration Motion - VAM}

\subsection{First-order Temporal Variation of the Acceleration}

Now, considering the differential equation

$$
d a=p \cdot d t
$$

where $p$ is the constant, the acceleration of this motion will be given by following equation:

$$
a(t)=p \cdot t+a_{o},
$$

where $a_{o}$ is the initial value of the acceleration (for $\mathrm{t}=0$ ). Applying to Eq. 5 into Eq. 1,

one can write $\int d v=\int\left(p \cdot t+a_{o}\right) d t$, whose solution provides a second-order equation in $t$ for velocity:

$$
v(t)=v_{o}+a_{o} t+\frac{p t^{2}}{2}
$$

and the corresponding displacement in this motion is given solving the integral:

$$
\int d S=\int\left(v_{o}+a_{o} t+\frac{p \cdot t^{2}}{2}\right) d t
$$

then, 


$$
S(t)=S_{o}+v_{o} t+\frac{a_{o} t^{2}}{2}+\frac{p \cdot t^{3}}{3.2}
$$

which is a third-order equation in $t$.

Figure 1 shows the plots representing equations 2, 3, 6, and 7. Figure 1(a) shows the velocity plot for UAM (Eq. 2), para $a=2 \mathrm{~m} / \mathrm{s}^{2}$, as well as the plot for velocity in the uniform motion (UM), for $\mathrm{v}=2 \mathrm{~m} / \mathrm{s}$. The plot for the second-order velocity equation (Eq. 6) is shown in Figure 1(b), the hatched area corresponds the displacement. Figure 1(c) allows the comparison of displacement in UAM and VAM (Eq. 7), for $p=2$.

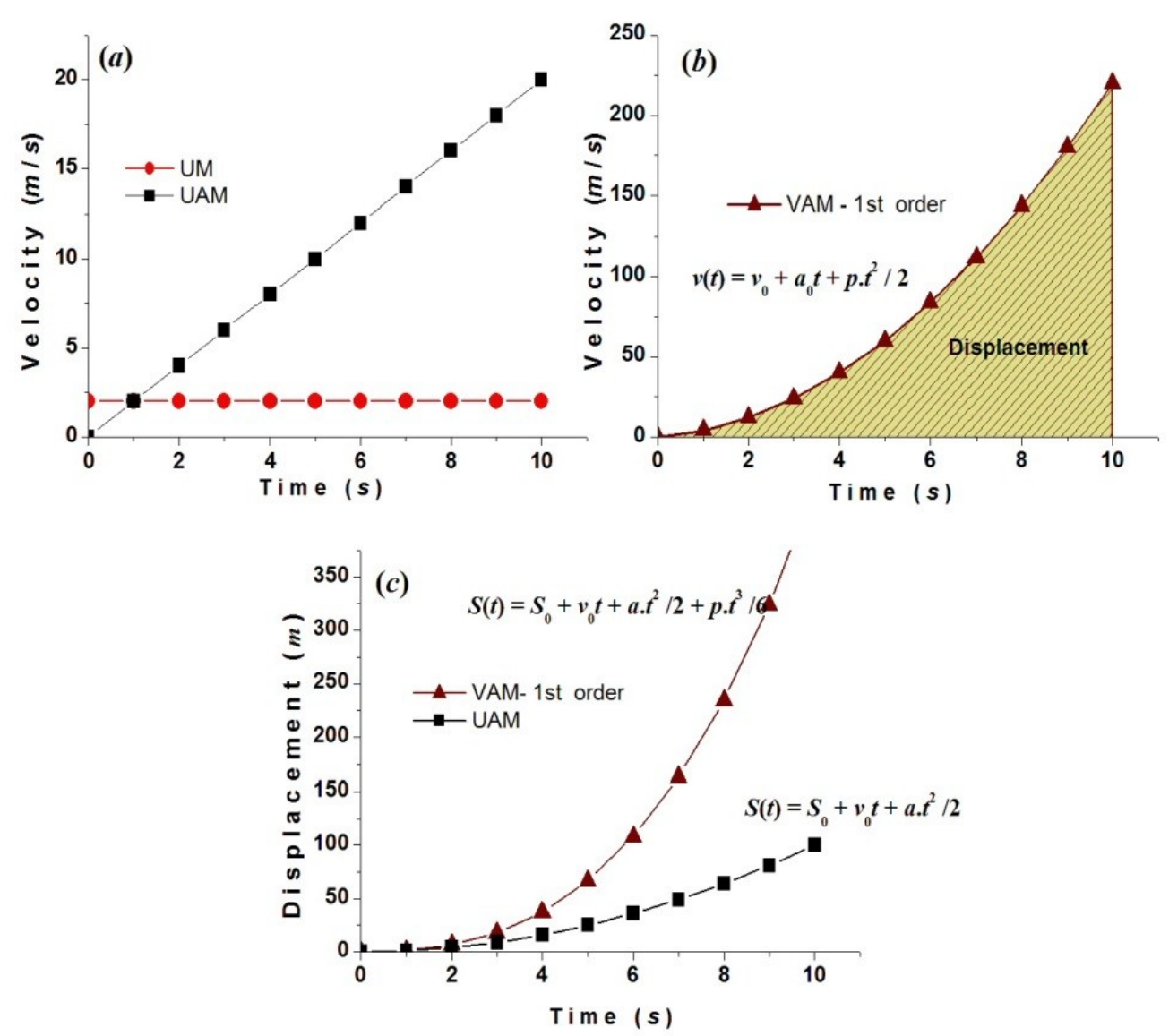

Figure 1: (a) Velocity varying with time for UM and UAM (Eq. 2). (b) Velocity varying with time, according to Eq. 6. (c) Displacement varying in time, according to Eq. 3 and Eq. 7 for p=2.

\subsection{Second-order Temporal Variation of the Acceleration}

From Eq. 7 we can find what will happen if $p$ the one himself varied over time, so that $d p=q d t$, being a constant. By following the same steps as above, we can make 


$$
\int d p=\int q d t
$$

and

$$
p=p_{o}+q \cdot t,
$$

and replacing Eq. 9 into Eq. 4, we can write that $\int d a=\int\left(p_{o}+q . t\right) d t$, which generates a second-order acceleration equation, that is:

$$
a(t)=a_{o}+p_{o} t+\frac{q \cdot t^{2}}{2}
$$

Substituting Eq. 10 into Eq. 1 and integrating, $\int d v=\int\left(p_{o} t+\frac{q t^{2}}{2}+a_{o}\right) d t$, we find a third-order equation for velocity:

$$
v(t)=v_{o}+a_{o} t+\frac{p_{o} t^{2}}{2}+\frac{q t^{3}}{3.2}
$$

and the displacement of body in this motion will be given from solution of

$$
\begin{aligned}
\int d S=\int\left(\frac{q t^{3}}{3.2}+\frac{p_{o} t^{2}}{2}+a_{o} t+v_{o}\right) d t \text {, being } & \\
S & =S_{o}+v_{o} t+\frac{a_{o} t^{2}}{2}+\frac{p_{o} t^{3}}{3.2}+\frac{q t^{4}}{4.3 .2}
\end{aligned}
$$

Thus, Eq. 12 allows to estimate the displacement of a body performing a variable acceleration motion. In this, the acceleration depends on $p$ (which varies with $t$ and $q$ is the proportionality constant) being the initial value $p=p_{o}$.

\section{Third-order Temporal Variation of the Acceleration}

We can continue from Eq. 12, now verifying the evolution of the motion if the $q$ also varies with time, being $d q=r d t$ and $r$ is constant. So, by following the same steps above, we can make $\int d q=\int r d t$, which gives 


$$
q(t)=q_{o}+r t
$$

and substituting Eq. 13 into Eq. 8 and integrating, we have that:

$$
p(t)=\frac{r t^{2}}{2}+q_{o} t+p_{o}
$$

which properly replaced into Eq. 4, $\int d a=\int\left(\frac{r t^{2}}{2}+q_{o} t+p_{o}\right) d t$, provides the third-order acceleration equation, which has the following form:

$$
a(t)=a_{o}+p_{o} t+\frac{q_{o} t^{2}}{2}+\frac{r t^{3}}{3.2}
$$

Replacing Eq. 15 into Eq. 1 and integrating, we get the equation that describes a fourthorder equation for velocity that is

$$
v=v_{o}+a_{o} t+\frac{p_{o} t^{2}}{2}+\frac{q_{o} t^{3}}{3.2}+\frac{r t^{4}}{4.3 .2}
$$

and the fifth-order equation for displacement is

$$
S=S_{o}+v_{o} t+\frac{a_{o} t^{2}}{2}+\frac{p_{o} t^{3}}{3.2}+\frac{q_{o} t^{4}}{4.3 .2}+\frac{r t^{5}}{5.4 .3 .2}
$$

\section{Velocity and Displacement Equations in Form General}

Eq. 16 forms a series in $t$, and can be written as follows 


$$
v=\frac{C_{o}}{0 !}+\frac{C_{1} t}{1 !}+\frac{C_{2} t^{2}}{2 !}+\frac{C_{3} t^{3}}{3 !}+\frac{C_{4} t^{4}}{4 !}
$$

that is,

$$
v_{i}=\sum_{i=0}^{n} \frac{C_{i} t^{i}}{i !}
$$

where $C_{o}=v_{o}, C_{1}=a_{o}, C_{2}=p_{o}, C_{3}=q_{o}, C_{4}=r_{o}$ e $i \in \mathrm{N}$, and Eq. 17 forms the following series

$$
S=S_{o}+\frac{C_{0} t^{1}}{1 !}+\frac{C_{1} t^{2}}{2 !}+\frac{C_{2} t^{3}}{3 !}+\frac{C_{3} t^{4}}{4 !}+\frac{C_{4} t^{5}}{5 !}
$$

Thus, the general form of equation of the displacement is:

$$
S_{i}=S_{0}+\sum_{i=0}^{n} \frac{C_{i} t^{i+1}}{(i+1) !}
$$

Figure 2 shows the graphs obtained with Eq. 18 and Eq. 20, which correspond to UM, UAM and VAM.
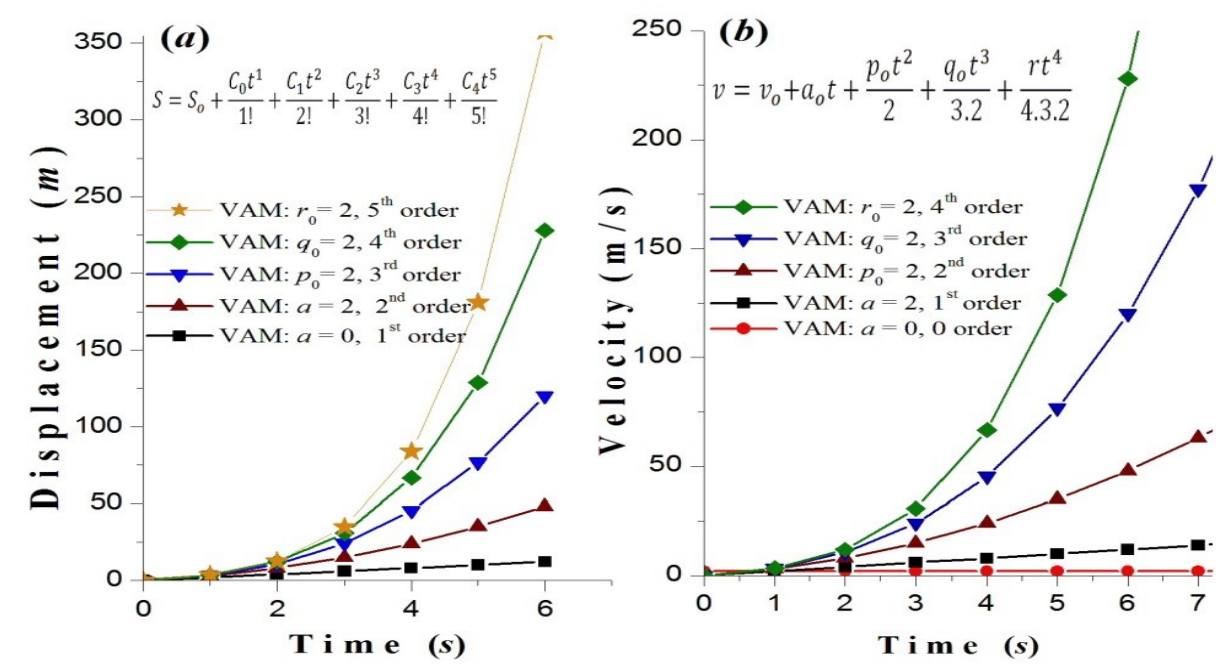

Figure 2: Displacement and velocity in VAM according to Eq. 18 and Eq. 20, respectively. 


\section{Analyzing the General form of the Equations for VAM}

From Eq. 21, it is possible to calculate the variation of space in time for any type of rectilinear motion. Each additional term in this equation represents the condition of a temporal variable involved in the described motion. Note that considering $C_{1}=\ldots=C_{\infty}=0$, Eq. 19 and Eq. 21 reduce to: $v=\frac{C_{o}}{0 !}=C_{o}=v_{o}=$ cte and $S=v_{o} t+S_{o}$, respectively, evidencing that the first two terms of Eq. 21(or Eq. 20) correspond to the displacement equation in UM. When $C_{2}=\ldots=C_{\infty}=0$, Eq. 19 and Eq. 21 reduce to Eq. 2 and Eq. 3, respectively, corresponding to the velocity and displacement in the UVM. For $C_{3}=\ldots=C_{\infty}=0$, equations generate from Eq. 19 and Eq. 21 also include, respectively, their terms of second and third orders: $v=\frac{p_{o} t^{2}}{2}+a_{o} t+v_{o}$ and $S=\frac{p_{o} t^{3}}{3.2}+\frac{a_{o} t^{2}}{2}+v_{o} t+S_{o}$, and so progressively.

Thus, it can be understood that Eq. 19 and Eq. 21 represent the most general form for calculating the velocity and displacement of a body in rectilinear motion. Table 1 summarizes the type and characteristics of the motion according to these equations, where each term represents the $i$-order temporal dependence of rectilinear motion, and $i$ can range from zero to infinity.

Table 1. Time-dependence order, type and characteristics of motion, according to Eq. 19 and Eq. 21.

\begin{tabular}{llcc}
\hline $\begin{array}{c}\text { Order } \\
(i)\end{array}$ & \multicolumn{1}{c}{ Motion Characteristics } & $\begin{array}{c}\text { Type of } \\
\text { Motion }\end{array}$ & $\begin{array}{c}\text { Constant Quantity } \\
\left(C_{i}\right)\end{array}$ \\
\hline \hline 0 & Constant velocity & UM & Velocity \\
1 & Constant Acceleration & UAM & Acceleration \\
2 & $\begin{array}{l}\text { Acceleration varying with the time, } \\
a(t)=p . t \text {, for } p=\text { constant. }\end{array}$ & VAM & $p$ \\
3 & $\begin{array}{l}\text { Acceleration varying with } a(t)=p . t, \\
\text { being } p(t)=q . t \text {, and } q=\text { constant. }\end{array}$ & VAM & $q$ \\
4 & $\begin{array}{l}\text { Acceleration varying with } a(t)=p . t, \\
\text { being } p(t)=q(t) . t, q(t)=r . t, \text { and } r= \\
\text { constant. }\end{array}$ & VAM & $r$ \\
\hline
\end{tabular}




\section{Conclusions}

Starting from the basic concept of acceleration as being the rate of variation of velocity in time, differential/integral development led us to a power series that can be understood as the most general form of the description of rectilinear motion. Each term in Eq. 19 and Eq. 21 represents an order of temporal dependence of the velocity and displacement, respectively. The first three terms in these equations refer to UM and UAM, and the others refer to VAM, being contributions due to temporal variations of parameters that influence on the acceleration.

\section{References}

[1] FOWLER, M. Naturally Accelerated Motion.

https://galileoandeinstein.phys.virginia.edu /lectures/gal_accn962.htm

[2] TAKIMOTO, E. História da Física na Sala de Aula. $1^{\mathrm{a}}$ ed., Rio de Janeiro: Ed. Livraria de Física, 2009.

[3] EVANS, M.; BROWN, P.; HUNT, D.; MATHEWS, D. Motion in a straight line. Suport Australian Mathematics Project. A guide for teachers. Calculus: Module 17. Editor Pitkethly J. Education Services Australia Ltd., 2013.

[4] ROQUE, T.; CARVALHO, J.B.P. Tópicos de História da Matemática. Rio de Janeiro: SBM, 2012. Coleção PROFMAT.

[5] NUSSENZVEIG, H.M. Curso de Física Básica: Mecânica. Vol. 1. 5ª edição. 2013. São Paulo: Ed. Edgard Blucher Ltda, 2013.

[6] THOMAS, G.B.; Weir M.D.; Hass, J. Calculus. Vol.1, 11th ed., Glenview: Addison-weslwy, 2000. 